\title{
Garcinia Multiflora Inhibits FPR1-Mediated Neutrophil Activation and Protects Against Acute Lung Injury
}

\author{
Yung-Fong Tsaia,b,c Shun-Chin Yang ${ }^{a, d}$ Wen-Yi Chang ${ }^{a} \quad$ Jih-Jung Chen ${ }^{e, f}$ \\ Chun-Yu Chen ${ }^{a, b, c}$ Shih-Hsin Chang ${ }^{a, g}$ Tsong-Long Hwang ${ }^{a, b, g, h}$
}

aGraduate Institute of Natural Products, College of Medicine, Chang Gung University, Taoyuan, bDepartment of Anesthesiology, Chang Gung Memorial Hospital, Taoyuan, 'Graduate Institute of Clinical Medical Sciences, College of Medicine, Chang Gung University, Taoyuan, dDepartment of Anesthesiology, Taipei Veterans General Hospital and National Yang-Ming University, Taipei, eFaculty of Pharmacy, School of Pharmaceutical Sciences, National Yang-Ming University, Taipei, fDepartment of Medical Research, China Medical University Hospital, Taichung, ${ }^{9}$ Research Center for Chinese Herbal Medicine, Research Center for Food and Cosmetic Safety, Graduate Institute of Health Industry Technology, College of Human Ecology, Chang Gung University of Science and Technology, Taoyuan, ${ }^{h}$ Chinese Herbal Medicine Research Team, Healthy Aging Research Center, Chang Gung University, Taoyuan, Taiwan

\section{Key Words}

Acute lung injury • Elastase - Formyl peptide receptor 1 - Garcinia multiflora - Neutrophil • Superoxide anion

\begin{abstract}
Background/Aims: Formyl peptide receptors (FPRs) recognize different endogenous and exogenous molecular stimuli and mediate neutrophil activation. Dysregulation of excessive neutrophil activation and the resulting immune responses can induce acute lung injury (ALI) in the host. Accordingly, one promising approach to the treatment of neutrophil-dominated inflammatory diseases involves therapeutic FPR1 inhibition. Methods: We extracted a potent FPR1 antagonist from Garcinia multiflora Champ. (GMC). The inhibitory effects of GMC on superoxide anion release and elastase degranulation from activated human neutrophils were determined with spectrophotometric analysis. Reactive oxygen species (ROS) production and the FPR 1 binding ability of neutrophils were assayed by flow cytometry. Signaling transduction mediated by GMC in response to chemoattractants was assessed with a calcium influx assay and western blotting. A lipopolysaccharide (LPS)-induced ALI mouse model was used to determine the therapeutic effects of GMC in vivo. Results: GMC significantly reduced superoxide anion release, the reactive oxidants derived therefrom, and elastase degranulation mediated through selective, competitive FPR1 blocking in $\mathrm{N}$-formyl-L-methionyl-L-leucyl-Lphenylalanine (fMLF)-stimulated human neutrophils. In cell-free systems, GMC was unable




\section{Cellular Physiology Cell Physiol Biochem 2018;51:2776-2793 \\ and Biochemistry Published online: 12 December $2018 \begin{aligned} & \text { DOI: } 2018 \text { The Author(s). Published by S. Karger AG, Basel } \\ & \text { www.karger.com/cpb }\end{aligned}$ \\ Tsai et al.: A Novel FPR1 Antagonist GMC Inhibits Neutrophilic Inflammation}

to scavenge superoxide anions or suppress elastase activity. GMC produced a right shift in fMLF-activated concentration-response curves and was confirmed to be a competitive FPR1 antagonist. GMC binds to FPR1 not only in neutrophils, but also FPR1 in neutrophil-like THP-1 and hFPR1-transfected HEK293 cells. Furthermore, the mobilization of calcium and phosphorylation of mitogen-activated protein kinases and Akt, which are involved in FPR1mediated downstream signaling, was competitively blocked by GMC. In an in vivo study, GMC significantly reduced pulmonary edema, neutrophil infiltration, and alveolar damage in LPSinduced ALI mice. Conclusion: Our findings demonstrate that GMC is a natural competitive FPR1 inhibitor, which makes it a possible anti-inflammatory treatment option for patients critically inflicted with FPR1-mediated neutrophilic lung damage.

(C) 2018 The Author(s)

Published by S. Karger AG, Basel

\section{Introduction}

Inflammation is a physical defense response to microorganism infection and pathologic progression that is largely mediated by neutrophil recruitment and activation [1]. However, dysregulation of neutrophil activation can be harmful to major organs and has been associated with the pathogenesis of many clinical diseases, such as acute lung injury (ALI), acute respiratory distress syndrome (ARDS), Alzheimer's disease, autoimmune diabetes, and rheumatoid arthritis [2-5]. As ALI and ARDS develop, a large number of neutrophils are activated and recruited into inflamed lungs. Poorly regulated neutrophils release massive quantities of superoxide anions and proteolytic enzymes, which can damage the alveolar capillary barrier and hinder pulmonary gas exchange [6]. Despite the development of numerous therapeutic strategies, mortality rates remain high among patients with ALI and ARDS [7].

G protein-coupled formyl peptide receptor 1 (FPR1) is a transmembrane receptor primarily found in neutrophils. These receptors are responsible for sensing various endogenous and exogenous molecular stimuli to mediate neutrophil activation during inflammation [8,9]. $\mathrm{N}$-formyl peptides derived from invading microorganisms or endogenous host mitochondria strongly bind to FPR1 to trigger septic or sterile inflammatory responses $[10,11]$. The binding of $N$-formyl peptides to FPR1 activates neutrophils and guides their migration into infected or injured tissues. Recent cellular and animal studies have proven the therapeutic effects of FPR1 antagonists $[12,13]$. Blockade of FPR1 reduces many of the essential functions of neutrophils associated with defense, such as superoxide anion generation, elastase release, chemotaxis, and phagocytosis [14]. One previous study reported that trauma hemorrhagic shock-induced lung damage and systemic inflammatory response syndrome in rats are associated with endogenous mitochondrial $N$-formyl peptides, which can be alleviated by the administration of FPR inhibitors [15]. Grommes [16] revealed that exogenous endotoxin induced FPR1-mediated lung neutrophil infiltration, with relief provided by FPR1 knockout. FPR1 antagonists also decrease neutrophil infiltration in cases of lipopolysaccharide (LPS)-induced ALI [13].

FPR1 antagonists are an emerging therapeutic target in the development of drugs to combat neutrophilic lung inflammation. However, only a few FPR1 antagonists have been studied [12]. Our research team examined the anti-inflammatory effects of extracts from the fruit of the evergreen Garcinia multiflora Champ., which is endemic to Taiwan, Hong Kong, and southern China. We named the fruit extraction from Garcinia multiflora Champ. as GMC. Studies have reported that G. multiflora has anti-inflammatory [17] and anti-HIV activity [18]. We previously reported that pure compounds from G. multiflora inhibit the generation of superoxide anions and elastase release in fMLF-stimulated neutrophils [17, 19]. Nonetheless, the pharmacological mechanisms and therapeutic effects of GMC remain to be elucidated.

In this study, we investigated the anti-inflammatory roles of GMC by conducting in vitro studies of neutrophil activation and an in vivo study of LPS-induced ALI in mice. Our results revealed that GMC significantly suppresses superoxide anion production, the reactive 


\section{Cellular Physiology Cell Physiol Biochem 2018;51:2776-2793 and Biochemistry Publisher \begin{tabular}{l|l} 
DOI: $10.1159 / 000495970$ & $\begin{array}{l}\text { (c) } 2018 \text { The Author(s). Published by S. Karger AG, Basel } \\
\text { www.karger.com/cpb }\end{array}$
\end{tabular} \\ Tsai et al:: A Novel FPR1 Antagonist GMC Inhibits Neutrophilic Inflammation}

oxidants derived therefrom, and elastase degranulation in $\mathrm{N}$-formyl peptide-stimulated neutrophils by selectively binding to FPR1 to block calcium mobilization as well as mitogenactivated protein kinase (MAPK) and Akt activation. Administration of GMC also greatly reduced endotoxin-induced ALI in mice, indicating GMC as a clinical therapeutic option for the treatment of neutrophil-related pulmonary inflammation.

\section{Materials and Methods}

\section{Plant extraction}

The dried fruit of G. multiflora ( $3 \mathrm{~kg}$ ) was cut into small pieces and immersed in $\mathrm{MeOH}(3 \times 10 \mathrm{~L}$ ) for 3 days for sequential extraction. Residue (330 g) was concentrated from $\mathrm{MeOH}$ extracts under vacuum and then partitioned into EtOAc and $\mathrm{H}_{2} \mathrm{O}$. Residue Fraction A (167 g) was concentrated from the EtOAc layer. After obtaining chromatographs from samples on silica gel, we subjected $120 \mathrm{~g}$ of Fraction A to elution using $\mathrm{CH}_{2} \mathrm{Cl}_{2}$, which yielded $77 \mathrm{mg}$ of GMC.

\section{Reagents}

Trp-Lys-Tyr-Met-Val-D-Met- $\mathrm{NH}_{2}$ (WKYMVm) was obtained from Tocris Bioscience (Ellisville, MO). Fluo3/AM and $N$-formyl-Nle-Leu-Phe-Nle-Tyr-Lys-fluorescein (FNLFNYK) were obtained from Molecular Probes (Eugene, OR). Methoxysuccinyl-Ala-Ala-Pro-Val-nitroanilide, rolipram, and N-[2-(p-Bromocinnamylamino) ethyl]-5-isoquinolinesulfonamide (H89) were purchased from Calbiochem (San Diego, CA). Water soluble tetrazolium-1 (WST-1) was purchased from Dojindo Laboratories (Kumamoto, Japan). Cyclic adenosine monophosphate (cAMP) immunoassay kits were obtained from GE Healthcare (Uppsala, Sweden). The antibody for p38 MAPK was purchased from Santa Cruz Biotechnology (Santa Cruz, CA), and other antibodies were obtained from Cell Signaling Technology (Danvers, MA). All other pharmacologic materials were purchased from Sigma-Aldrich (St. Louis, MO).

\section{Human neutrophil preparation}

All human research protocols were examined by the Institutional Review Board of Chang Gung Medical Foundation. Healthy volunteers who had not been taking any medication within at least the 2 previous weeks provided informed consent prior to enrollment in the study. Blood samples were donated only from healthy young people (20-30 years of age). Buffy coats containing neutrophils were obtained from donated whole blood using a dextran sedimentation assay, as described in [20]. The buffy coats were then collected using differential centrifugation in a Ficoll Hypaque. Erythrocytes were lysed using a hypotonic solution on ice. Samples were washed and resuspended in iced Hank's balanced salts solution (HBSS) to obtain viable neutrophils of no less than $98 \%$ purity.

\section{Cell culture}

THP-1 cells were grown in Roswell Park Memorial Institute medium 1640 supplemented with glutamine (2 mM), fetal bovine serum (FBS, 10\%), and antibiotics. THP-1 cells then underwent induced cell differentiation using dibutyryl cAMP $(300 \mu \mathrm{M})$ for 2 days before being centrifuged and resuspended in growth medium [13].

HEK293 cells were cultured in Dulbecco's modified Eagle's medium containing FBS (10\%), glutamine ( $2 \mathrm{mM}$ ), and antibiotics. HEK293 cells were transfected with the human FPR1 gene (NM_002029; OriGene, Rockville, MD) using a pCMV6-AC vector for 3 days in accordance with the manufacturer's instructions [13].

\section{Determination of superoxide anion and reactive oxygen species production}

The extracellular superoxide anion levels in neutrophils were determined using a spectrophotometer (U-3010; Hitachi, Tokyo) and are expressed as the reduction in the quantity of ferricytochrome $c$. Following pre-incubation with ferricytochrome $c$, neutrophils were primed with or without cytochalasin $\mathrm{B}$ at $37^{\circ} \mathrm{C}$ for $3 \mathrm{~min}$. For cell activation, neutrophils were pretreated with vehicle (dimethyl sulfoxide [DMSO]) or GMC for 5 min followed by a 10-min stimulation with fMLF (FPR1 agonist), WKYMVm (FPR1/FPR2 agonist), $\mathrm{NaF}$ (G protein activator), or PMA (protein kinase $\mathrm{C}$ activator). The changes in absorbance were analyzed continuously at $550 \mathrm{~nm}$ by a spectrophotometer. DHR123 dye was used to probe reactive oxygen species 


\section{Cellular Physiology Cell Physiol Biochem 2018;51:2776-2793 \begin{tabular}{ll|l} 
and Biochemistry Published onIIne: I2 December 2018 & $\begin{array}{l}\text { (c) } 2018 \text { The Author(s). Published by S. Karger AG, Basel } \\
\text { www.karger.com/cpb }\end{array}$ \\
\hline
\end{tabular} \\ Tsai et al.: A Novel FPR1 Antagonist GMC Inhibits Neutrophilic Inflammation}

(ROS) levels in the neutrophils. ROS is a reactive oxidant derived from superoxide anion. Following incubation with DHR123 dye for $12 \mathrm{~min}$ and DMSO or GMC for $5 \mathrm{~min}$, neutrophils were induced via fMLF. The fluorescence intensity was determined as an indication of ROS levels using flow cytometry (FACSCalibur ${ }^{\mathrm{TM}}$; BD Bioscience, San Jose, CA) [20].

\section{Measurement of elastase release}

Elastase release is expressed as the eliminating ability for the substrate methoxysuccinyl-AlaAla-Pro-Val-p-nitroanilide determined by spectrophotography at $405 \mathrm{~nm}$. Neutrophils pre-mixed with elastase substrate $(0.1 \mathrm{mM})$ were incubated with DMSO or GMC at $37^{\circ} \mathrm{C}$ for $5 \mathrm{~min}$ and stimulated using fMLF, WKYMVm, NaF, or leukotriene B4 (LTB4, BLT1 receptor agonist). Neutrophils were primed using cytochalasin B for 3 min prior to cell activation. Data are presented as the percentages of the levels obtained from the control group [20].

Assays of the scavenging effects of superoxide anions and dipenyl picryl hydrazyl radicals

A xanthine/xanthine oxidase system was used to evaluate the scavenging effects of superoxide anions. Test samples were incubated with WST-1 (300 $\mu \mathrm{M})$, Tris (pH 7.4, $50 \mathrm{mM})$, and xanthine oxidase (0.02 U/ $\mathrm{ml})$. Following the administration of xanthine $(0.1 \mathrm{mM})$ to the sample solution, WST- 1 was eliminated using superoxide anions. The radical scavenging effects are presented as the change in absorbance as determined using spectrophotography at $450 \mathrm{~nm}$ at $30^{\circ} \mathrm{C}$. In dipenyl picryl hydrazyl (DPPH) scavenging assays, DMSO or GMC were added to the ethanol buffer of DPPH $(0.1 \mathrm{mM})$. The change in absorbance was measured at $30^{\circ} \mathrm{C}$ at $517 \mathrm{~nm}$, and the data were compared with the data obtained from the control [20].

\section{Analysis of the lactate dehydrogenase level}

Lactate dehydrogenase (LDH) levels were detected using a commercial kit (Promega, Madison, WI). LDH levels are presented as the relative percentage of the total LDH. Total LDH levels were measured by lysing the cells using Triton X-100 (0.1\%) [21].

\section{Receptor binding assay}

Fluorescence-activated cell sorting (FACS) assays were used to characterize receptor binding [13]. A fluorescent analog of FMLF (FNLFNYK) was adopted for the analysis of binding ability to FPR1. All sample cells were pretreated for 5 min with DMSO, GMC, or fMLF and stained with FNLFNYK at $4{ }^{\circ} \mathrm{C}$. Cells were then resuspended in HBSS and analyzed using flow cytometry with fMLF as positive control.

\section{Determination of cAMP concentrations}

Neutrophils were treated with DMSO or GMC for 5 min before stimulation with fMLF, with rolipram as positive control. The assay was blocked by the administration of dodecyltrimethylammonium bromide $(0.5 \%)$. Following centrifugation at $3,000 \times g$, the supernatant of the samples was obtained to measure cAMP levels using a commercial enzyme immunoassay kit (Amersham Biosciences, Buckinghamshire, UK) [21].

\section{Determination of calcium concentrations in neutrophils}

Neutrophils stained with Fluo-3/AM dye $(2 \mu \mathrm{M})$ were used to assess calcium influx in response to chemoattractants. Cytoplasmic calcium concentrations were assayed using a spectrofluorometer at $37^{\circ} \mathrm{C}$. The excitation and emission wavelengths were 488 and $520 \mathrm{~nm}$, respectively. Following treatment with DMSO or GMC, fMLF, WKYMVm, or LTB4 were administered to induce calcium mobilization. The peak intracellular calcium concentration $\left(\left[\mathrm{Ca}^{2+}\right]_{\mathrm{i}}\right)$ was calculated by determination of the fluorescence intensity based on the protocol described in our previous study [21].

\section{Western immunoblotting analysis}

Following incubation with the vehicle control (DMSO) or GMC, neutrophils were stimulated with fMLF for $30 \mathrm{~s}$ or with WKYMVm, PMA, or LTB4 for $60 \mathrm{~s}$. Lysates of neutrophils were obtained for western blotting analysis after separation via centrifugation at $14,000 \times g$. We used $12 \%$ sodium dodecyl sulfatepolyacrylamide gel electrophoresis to determine the levels of each protein target in each of the cytoplasmic extracts. The separated proteins were blotted onto transfer membrane and treated with primary antibodies 


\section{Cellular Physiology Cell Physiol Biochem 2018;51:2776-2793 \\ \begin{tabular}{ll|l} 
and Biochemistry & $\begin{array}{l}\text { DOl: 10.1159/000495970 } \\
\text { Published onlIne: 12 December } 2018\end{array}$ & $\begin{array}{l}\text { ( } 2018 \text { The Author(s). Published by S. Karger AG, Basel } \\
\text { www.karger.com/cpb }\end{array}$ \\
\hline
\end{tabular}}

Tsai et al.: A Novel FPR1 Antagonist GMC Inhibits Neutrophilic Inflammation

and anti-rabbit horseradish peroxidase-conjugated secondary antibodies (Cell Signaling Technology). The intensity of the blotted proteins was determined using a chemiluminescence substrate (Amersham Biosciences, Piscataway, NJ) on a UVP Biospectrum imager (UVP, Upland, CA) $[13,20]$.

\section{Experimental animals}

The protocol of this study protocol was based on the instructions found in The Guide for Care and Use of Laboratory Animals issued by the Taiwanese government. C57BL/6 mice (BioLasco, Ilan, Taiwan) underwent environmental adaptation for a period of 7 days prior to the animal study.

\section{LPS-induced ALI mouse model}

Twenty-four male mice (20-25 g, 7-8 weeks old) underwent general anesthesia through the intraperitoneal administration of Zoletil $50(30 \mu \mathrm{g} / \mathrm{g})$ and Xylazine $(6 \mu \mathrm{g} / \mathrm{g})$. After being anesthetized, the mice were intratracheally instilled with an LPS spray (160 ng/g; Sigma-Aldrich) from E. coli (serotype 0111:B4) $[13,20]$. Animals were randomly separated into groups to receive GMC $(100 \mathrm{mg} / \mathrm{kg})$ or vehicle via the intraperitoneal route $1 \mathrm{~h}$ prior to the induction of lung injury. The animals were divided into four groups: sham, GMC only, LPS only, and LPS+GMC. Mouse lungs were removed under anesthesia after $6 \mathrm{~h}$. The left lung was fixed in buffered formalin (10\%) for histologic examination. The right upper lobes were analyzed for lung water content, and the other lobes of the right lung were assayed for myeloperoxidase (MPO) activity. Water content in the lungs was characterized by the wet-to-dry weight ratio.

\section{Measurement of MPO levels}

Harvested organs were homogenized in ice-cold PBS buffer ( $50 \mathrm{mM}, \mathrm{pH} 6.0)$ using a homogenizer. The homogenate was centrifuged at $12,000 \times g\left(4^{\circ} \mathrm{C}\right)$ for $20 \mathrm{~min}$ and the supernatant was recovered. The level of MPO in the supernatant was characterized as the degree of oxidation of $o$-dianisidine dihydrochloride (Sigma-Aldrich) using a spectrophotometer at $405 \mathrm{~nm}$. The results were normalized to the protein content of the samples as determined using the Bradford method (Bio-Rad Laboratories, Hercules, CA) [20].

\section{Histopathology examination}

Lung samples were immersed in formalin (10\%) for 1 day and embedded in paraffin blocks before being cut into 5 - $\mu$ m-thick pieces. Tissue sections were stained using hematoxylin and eosin or immunohistochemistry as described previously [20]. Formalin-fixed sections embedded in paraffin underwent immunohistochemical analysis using Ly-6G (Gr-1) protein. Ly-6G (Gr-1) is a myeloid differentiation antigen and a good indicator for the identification of peripheral neutrophils. In this experiment, we used rat anti-mouse-Ly-6G (Gr-1) monoclonal primary antibodies (eBioscience, San Diego, CA) at a 1:200 dilution for staining. Microscopic images were obtained under a light microscope.

\section{Statistical analysis}

Experiment data are presented as the mean \pm standard error of the mean (SEM). Statistical analysis included the Student's $t$-test, one- or two-way analysis of variance, and Bonferroni's multiple-comparison test (SigmaPlot software, Systat Software, Inc., San Jose, CA). A $p$ value $<0.05$ was considered to indicate a significant difference between two groups.

\section{Results}

GMC reduces superoxide anion release, elastase degranulation, and ROS production in fMLF-stimulated human neutrophils

Respiratory burst and degranulation are the basic inflammatory responses observed in neutrophils. Our data revealed that GMC greatly reduced superoxide anion generation and elastase degranulation in fMLF-stimulated neutrophils, with half-maximal inhibitory concentration $\left(\mathrm{IC}_{50}\right.$ ) values of $3.89 \pm 1.17$ and $4.33 \pm 0.95 \mathrm{ng} / \mathrm{ml}$, respectively (Fig. $1 \mathrm{~A}$ and B). fMLF is a selective FPR1 agonist. In flow cytometric analysis, GMC decreased intracellular ROS production in fMLF-stimulated human neutrophils (Fig. 1C). Because GMC did not induce LDH release, even at a concentration of $2 \mu \mathrm{g} / \mathrm{ml}$ (data not shown), GMC is not likely 


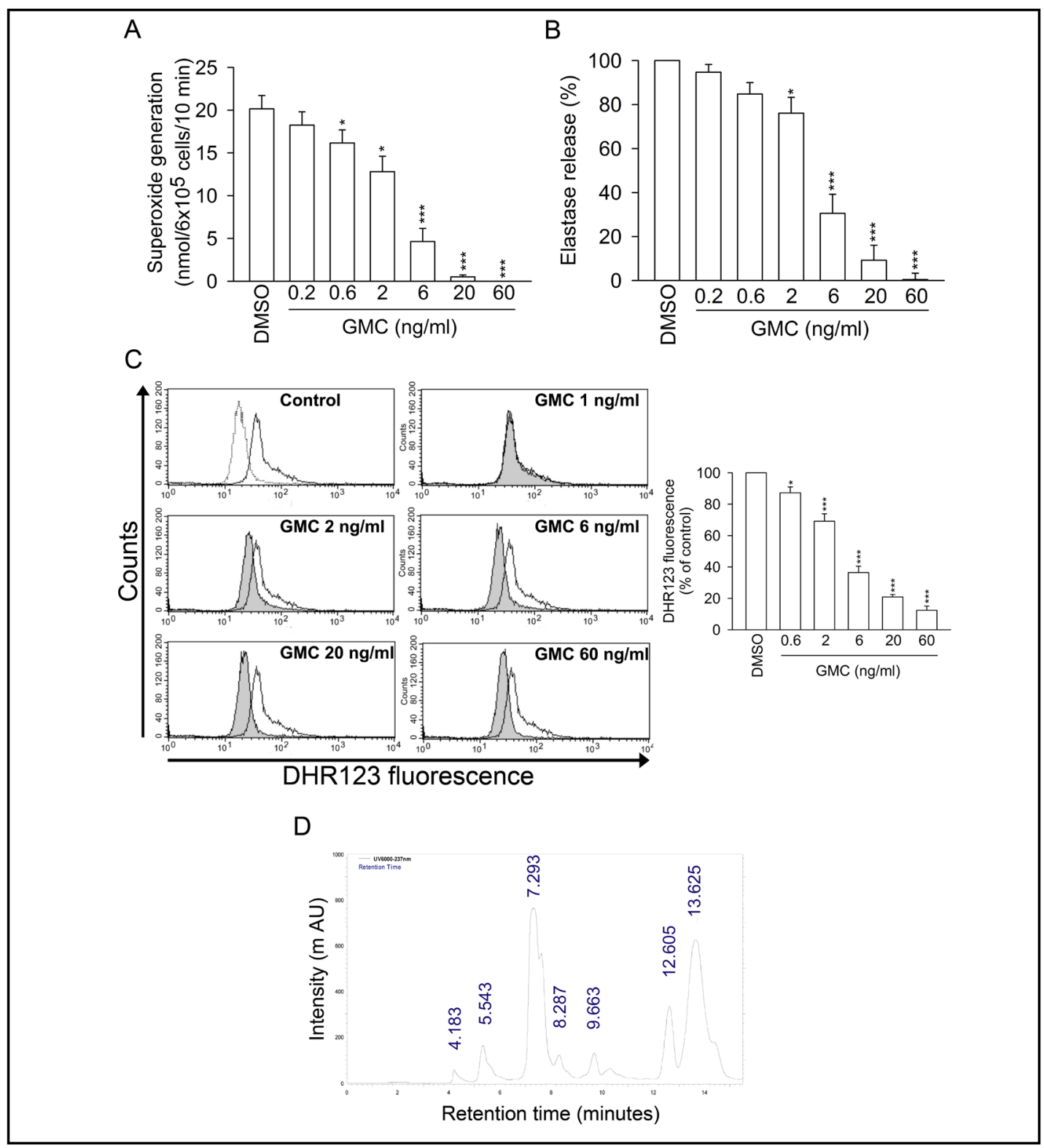

Fig. 1. GMC inhibits superoxide anion release, elastase degranulation, and ROS production in fMLFstimulated human neutrophils. Neutrophils were treated with or without GMC $(0.2-60 \mathrm{ng} / \mathrm{ml})$ prior to being activated with fMLF (100 nM). The levels of (A) superoxide anion release and elastase degranulation were determined via spectrophotometric analysis. (C) Neutrophils stained with DHR123 dye were treated with or without GMC (0.6-60 ng/ml) followed by stimulation with fMLF (100 nM) and flow cytometry monitoring. The gray area indicates the basal group comprising neutrophils without any fMLF or GMC treatment. The black lines indicate the treatment groups. (D) Chromatographic analysis of GMC. Experiments were conducted independently eight times for A and B and five times for C. Values are expressed as mean \pm SEM. ${ }^{*} \mathrm{p}<0.05,{ }^{* * *} \mathrm{p}<0.001$ compared with the control.

to be cytotoxic to human neutrophils. GMC was obtained via ethyl acetate extraction from a novel active fraction of a medicinal herb in conjunction with high-performance liquid chromatography (HPLC) to ensure quality control. A fingerprint chromatogram of GMC is shown in Fig. 1D. The full-scan assay revealed that separation at a wavelength of $237 \mathrm{~nm}$ was superior to that at other wavelengths. A group of peaks and a characteristic peak at 7.293 min of retention time were observed in the fingerprint chromatogram (Fig. 1D). 
GMC fails to directly scavenge superoxide anions or suppress elastase activity

We used a xanthine/xanthine oxidase system and DPPH assays to evaluate the direct effects of superoxide anion-scavenging and anti-oxidation. Even at a high dose $(2 \mu \mathrm{g} / \mathrm{ml})$, GMC remained nonreactive in these cell-free systems (Fig. $2 \mathrm{~A}$ and $\mathrm{B}$ ). Superoxide dismutase and $\alpha$-tocopherol were used as positive controls. As shown in Fig. 2C, GMC did not have a direct effect on the inhibition of elastase activity.

GMC does not inhibit superoxide anion release or elastase degranulation in non-FPR1 agonistactivated neutrophils

To examine the anti-inflammatory effects of GMC in non-FPR1 agonist-activated neutrophils, we used WKYMVm (dual FPR1/FPR2 agonist), PMA (protein kinase $\mathrm{C}$ activator), LTB4 (BLT1 receptor agonist), or $\mathrm{NaF}$ (direct $\mathrm{G}$ protein activator) to trigger neutrophil functions. GMC failed to reduce superoxide anion release or elastase degranulation in non-FPR1 agonist-stimulated cells (Fig. 3).

GMC competes with the receptor binding of the FPR1-specific ligand FNLFNYK in neutrophils

Receptor binding analysis based on flow cytometry was used to assay theFPR1 binding affinity of GMC. FNLFNYK (a fluorescently labeled FPR1 ligand) is an fMLF analog. fMLF (used as a positive control) almost entirely blocked the binding affinity of FNLFNYK to neutrophils at a dose of $10 \mu \mathrm{M}$. GMC notably reduced the linkage of FNLFNYK to FPR1 in a dose-dependent manner, as did the positive control fMLF (Fig. 4A and B). The concentrationresponse curve of fMLF in superoxide production is shown in Fig. 4C. GMC showed a distinct right shift in the concentration-response curves of fMLF for superoxide anion release, confirming GMC as a competitive FPR1 inhibitor.

GMC binds FPR1 in non-neutrophil cells

The inhibition of FPR1 by GMC was reproduced in non-neutrophil cells, including dibutyryl cAMPdifferentiated THP-1 and hFPR1-transfected HEK293 cells. Again, GMC dose-dependently reduced the FPR1 binding of FNLFNYK in THP-1 and HEK293 cells (Fig. 5). GMC showed specificity for FPR1 binding in FPR1-expressing cells.

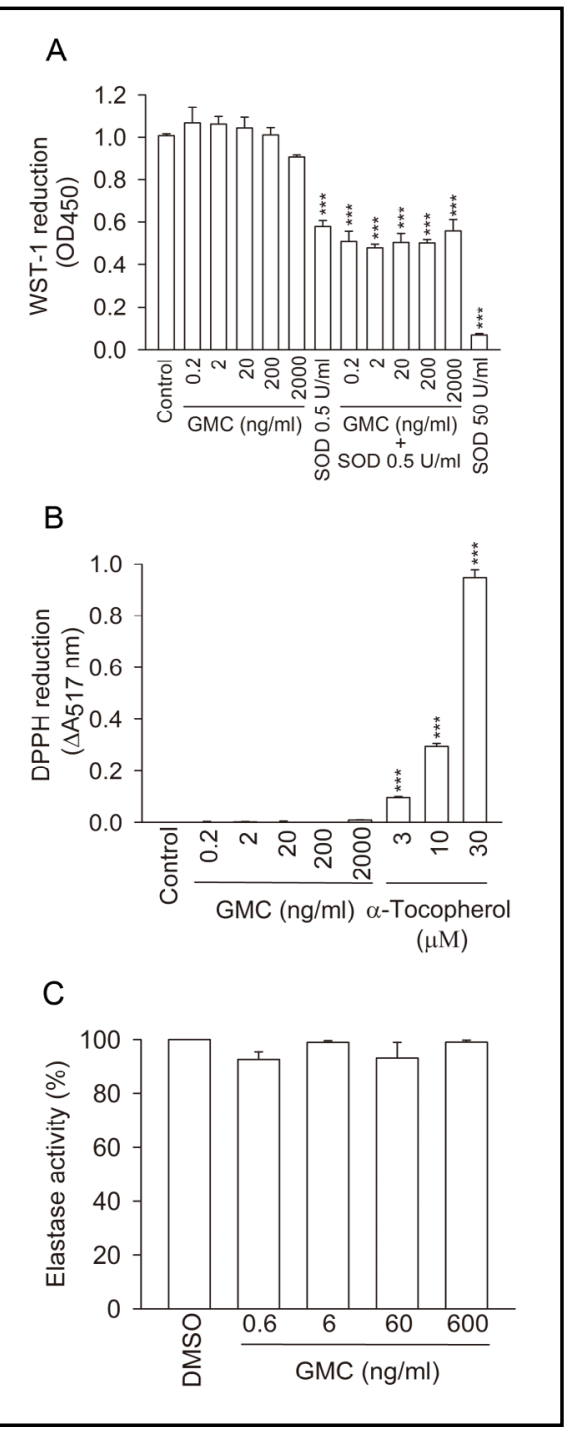

Fig. 2. GMC does not have inhibitory effects in cell-free systems. Reductions in (A) WST-1 and (B) DPPH were assayed spectrophotometrically at 450 and 517 nm, respectively. (C) Conditioned medium was produced from the supernatant of activated neutrophils, followed by treatment with or without GMC prior to substrate addition. All experiments were conducted independently three times. Values are expressed as mean \pm SEM. ${ }^{* * *} \mathrm{p}<0.001$ compared with the control. SOD, superoxide dismutase. 

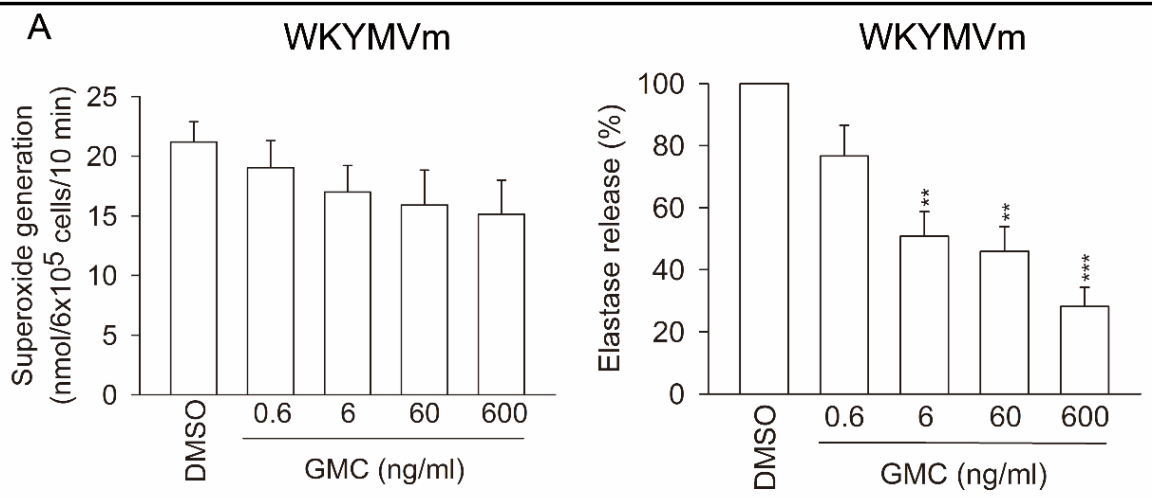

B

PMA

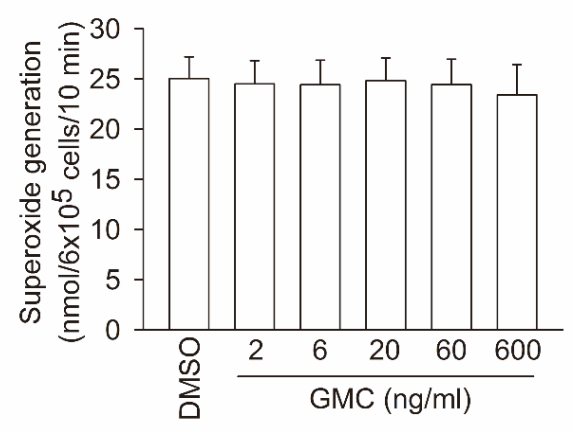

$\mathrm{D}$

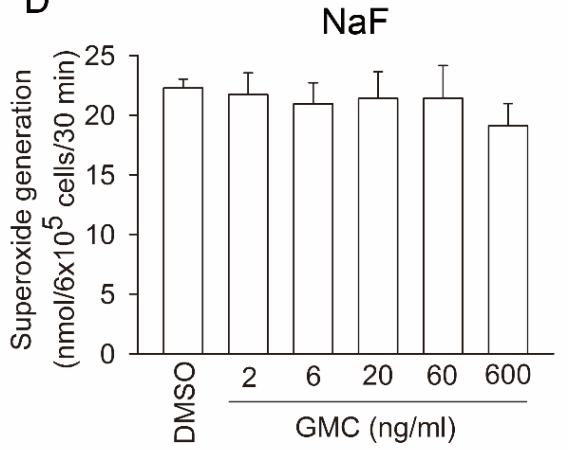

C

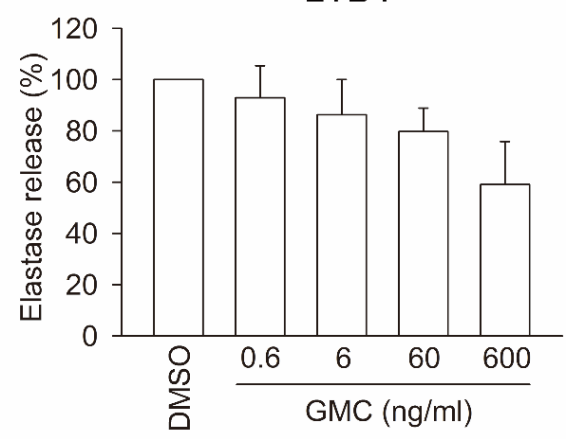

Fig. 3. GMC fails to inhibit superoxide anion release and elastase degranulation in non-FPR1 agoniststimulated neutrophils. Neutrophils were treated with or without GMC $(0.6-600 \mathrm{ng} / \mathrm{ml})$ and activated with (A) WKYMVm (2 nM), (B) PMA (5 nM), (C) LTB4 (100 nM), or (D) NaF (20 mM). Superoxide anion production or elastase release was determined using spectrophotometric analysis. Experiments were conducted independently four times for A and B, five times for C, and three times for D. Values are expressed as mean \pm SEM. ${ }^{* *} \mathrm{p}<0.01,{ }^{* * *} \mathrm{p}<0.001$ compared with the control.

The inhibitory effects of GMC are not mediated through protein kinase A signaling

cAMP/PKA has been closely associated with negative regulatory effects in human neutrophils [20]. The protein kinase A (PKA) antagonist H89 was unable to abolish the inhibitory effects of GMC on superoxide anion release and elastase degranulation (Fig. 6A and B). As shown in Fig. 6C, rolipram (phosphodiesterase 4 inhibitor), but not GMC, elevated intracellular cAMP concentrations in fMLF-stimulated neutrophils. Collectively, our results confirm that the suppressive effects of GMC are not associated with the cAMP/PKA signaling pathway. 

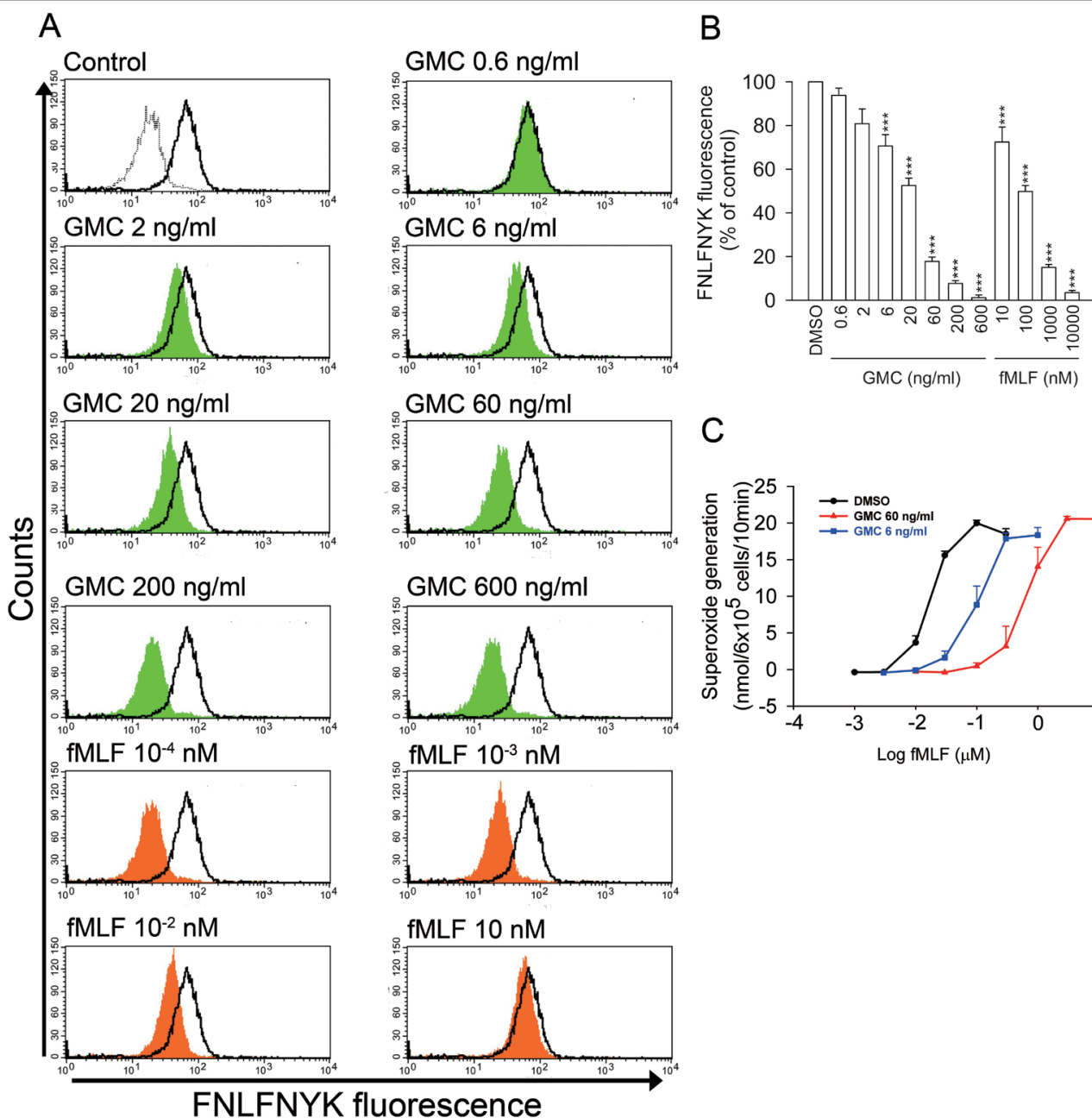

C

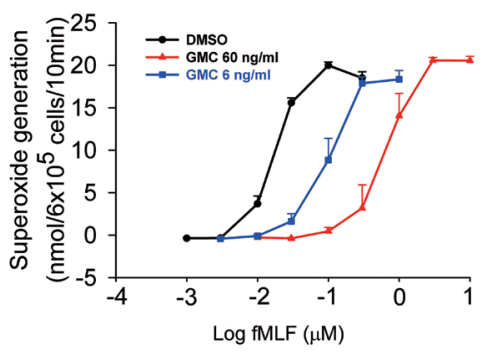

Fig. 4. GMC blocks receptor binding of FNLFNYK and exerts competitive inhibitory effects in human neutrophils. (A) Neutrophils were treated with GMC or fMLF $(10 \mu \mathrm{M})$ for 5 min and then stained with the fluorescent FPR1 ligand FNLFNYK (4 nM). The green or orange area indicates DMSO alone in the absence of FNLFNYK. The black lines indicate testing groups with GMC or fMLF in the presence of FNLFNYK. (B) The mean fluorescence intensity (MFI) was compared by reference to the control group (100\%) (C) Neutrophils were treated with GMC ( 6 and $60 \mathrm{ng} / \mathrm{ml}$ ) for $5 \mathrm{~min}$. Superoxide anion production was activated using increasing concentrations of fMLF (1.0-10000 nM). All experiments were conducted independently three or four times. ${ }^{* * *} \mathrm{p}<0.001$ compared with the control.

GMC specifically reduces $f M L F$-induced $\mathrm{Ca}^{2+}$ mobilization in neutrophils

$\mathrm{Ca}^{2+}$ mobilization is associated with numerous inflammation-related reactions in neutrophils. Activation of $\mathrm{G}$ protein-coupled receptors results in two phases of calcium mobilization in neutrophils. Initially, activation of $\mathrm{G}$ protein-coupled receptors induces phospholipase C $\beta$ and IP3 to trigger rapid calcium release from intracellular endoplasmic reticulum. Then, a prolonged $\mathrm{Ca}^{2+}$ influx develops after $\mathrm{Ca}^{2+}$ release-activated $\mathrm{Ca}^{2+}$ channels are activated [22]. The cytosolic $\mathrm{Ca}^{2+}$ elevation will rapidly diminish to reach basal values within several minutes [23]. We examined the effects of GMC on $\mathrm{Ca}^{2+}$ signaling in activated neutrophils. GMC significantly reduced the $\left[\mathrm{Ca}^{2+}\right]_{i}$ peak induced by fMLF in a dose-dependent manner (Fig. 7A). In contrast, the $\left[\mathrm{Ca}^{2+}\right]_{\mathrm{i}}$ peak induced by other stimulants (WKYMVm and LTB4) was unaffected by GMC (Fig. 7B and C). These findings indicate that GMC specifically suppresses $\mathrm{Ca}^{2+}$ signals in FPR1 agonist-stimulated neutrophils. 
A
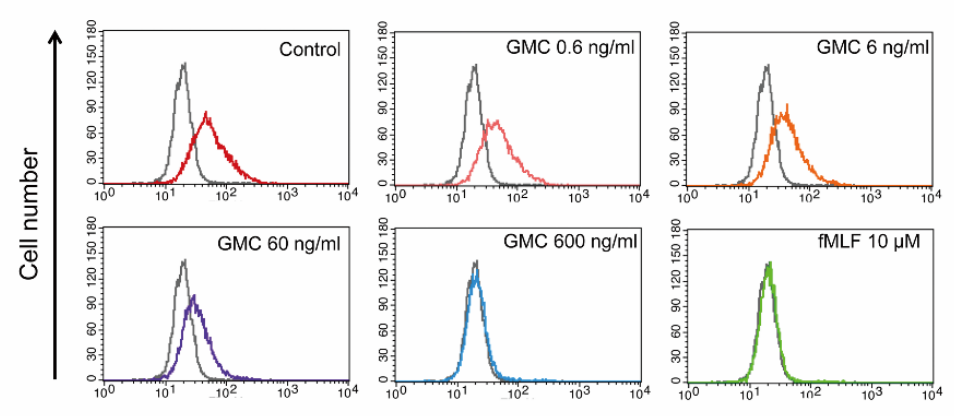

FNLFNYK fluorescence

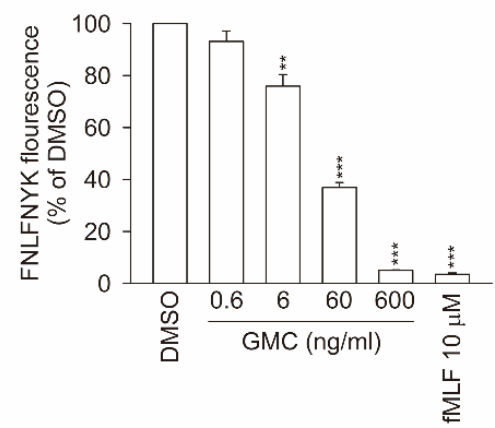

B
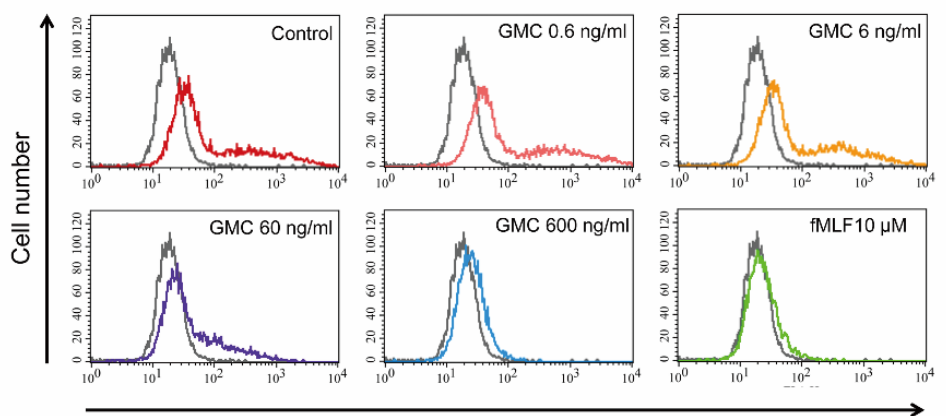

FNLFNYK fluorescence

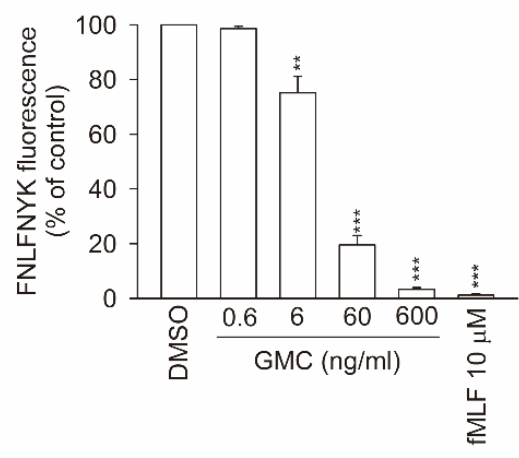

Fig. 5. GMC blocks the binding of FNLFNYK to FPR1 in non-neutrophil cultured cells. (A) Differentiated THP-1 and (B) hFPR1-transfected HEK293 cells were treated with GMC (0.6-600 ng/ml) or fMLF $(10 \mu \mathrm{M})$ for 5 min and then stained with the fluorescent FPR1 ligand FNLFNYK (4 nM). The black line denotes the basal group, which was incubated using DMSO only in the absence of FNLFNYK. The colored lines denote the test groups, which were administered DMSO, GMC, or fMLF in the presence of FNLFNYK. The MFI was compared with a reference control group (100\%). All experiments were conducted independently three times. ${ }^{* *} \mathrm{p}<0.01,{ }^{* * *} \mathrm{p}<0.001$ compared with the control.

\section{KARGER}


Fig. 6. $\quad$ cAMP/PKA signaling does not mediate the inhibitory effects of GMC. Neutrophils were pretreated with a PKA inhibitor, $\mathrm{H} 89(3 \mu \mathrm{M})$, prior to the addition of GMC. (A) Superoxide production and (B) elastase degranulation were stimulated using fMLF. (C) Cells were incubated with GMC (0.6$600 \mathrm{ng} / \mathrm{ml}$ ) or rolipram (3 $\mu \mathrm{M}$, positive control) with or without fMLF (100 nM). cAMP levels were measured using ELISA kits. All experiments were conducted independently three or four times. Values are expressed as mean \pm SEM. ${ }^{*} \mathrm{p}<0.05, \quad{ }^{* *} \mathrm{p}<0.01$, $* * * \mathrm{p}<0.001 \quad$ compared with the control. ${ }^{\# \#} \mathrm{p}<0.01$ versus fMLF alone.

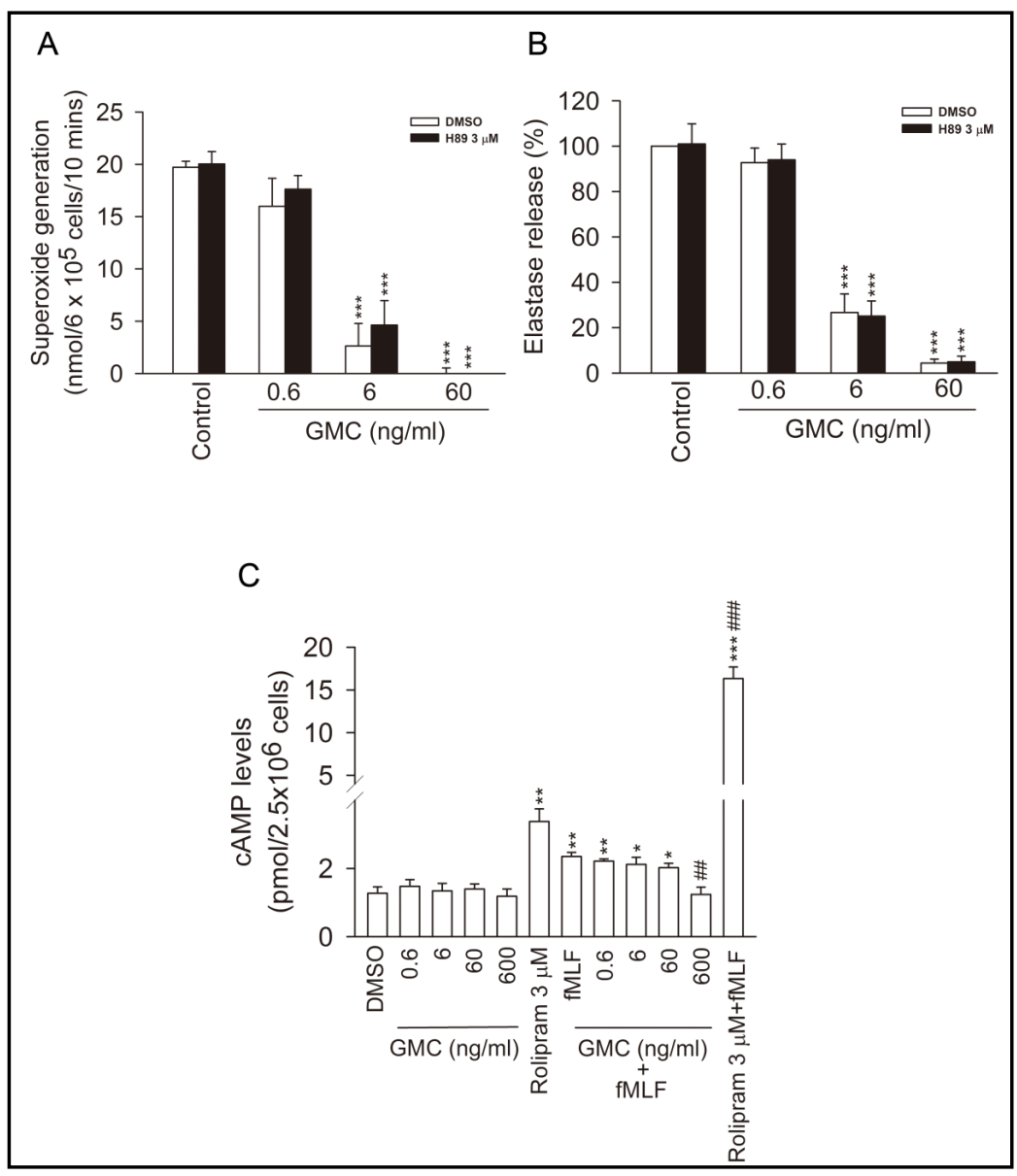

GMC attenuates MAPK and Akt phosphorylation with high specificity in fMLF-stimulated neutrophils

In the next experiments, we evaluated the effects of GMC on the phosphorylation of MAPK and Akt proteins. Our results revealed the rapid phosphorylation of MAPKs and Akt in fMLF-, WKYMVm-, PMA-, and LTB4-activated neutrophils. GMC specifically inhibited the fMLF-induced phosphorylation of MAPKs and Akt in human neutrophils (Fig. 8A). GMC did not inhibit the phosphorylation of MAPKs or Akt in WKYMVm-, PMA-, or LTB4-activated human neutrophils (Fig. 8B and C).

GMC ameliorates lung inflammation in an LPS-induced ALI mouse in vivo

Histological analysis of LPS-induced ALI in mice revealed neutrophil infiltration (Ly6G ${ }^{+}$ cells), interstitial edema, and alveolar wall thickening. GMC treatment reduced neutrophil infiltration and thickening of the alveolar wall in the presence of LPS. GMC alone and sham groups showed no signs of airspace inflammation or a reduction in neutrophil infiltration. Thus, GMC reduced the effects of lung injury in an LPS-induced ALI mouse model (Fig. 9A).

The wet-to-dry weight ratio of mouse lungs was used to indicate the degree of pulmonary edema. The calculated ratios in LPS-treated lung exceeded those of the sham groups. GMC treatment clearly mediated the increase in the wet-to-dry weight ratios in LPS-treated lungs (Fig. 9B). Moreover, MPO activity mirrors neutrophil infiltration [24]. LPS treatment significantly increased MPO activity compared with the sham group while GMC administration significantly suppressed the increase in MPO activity in the LPS-treated groups (Fig. 9C). 


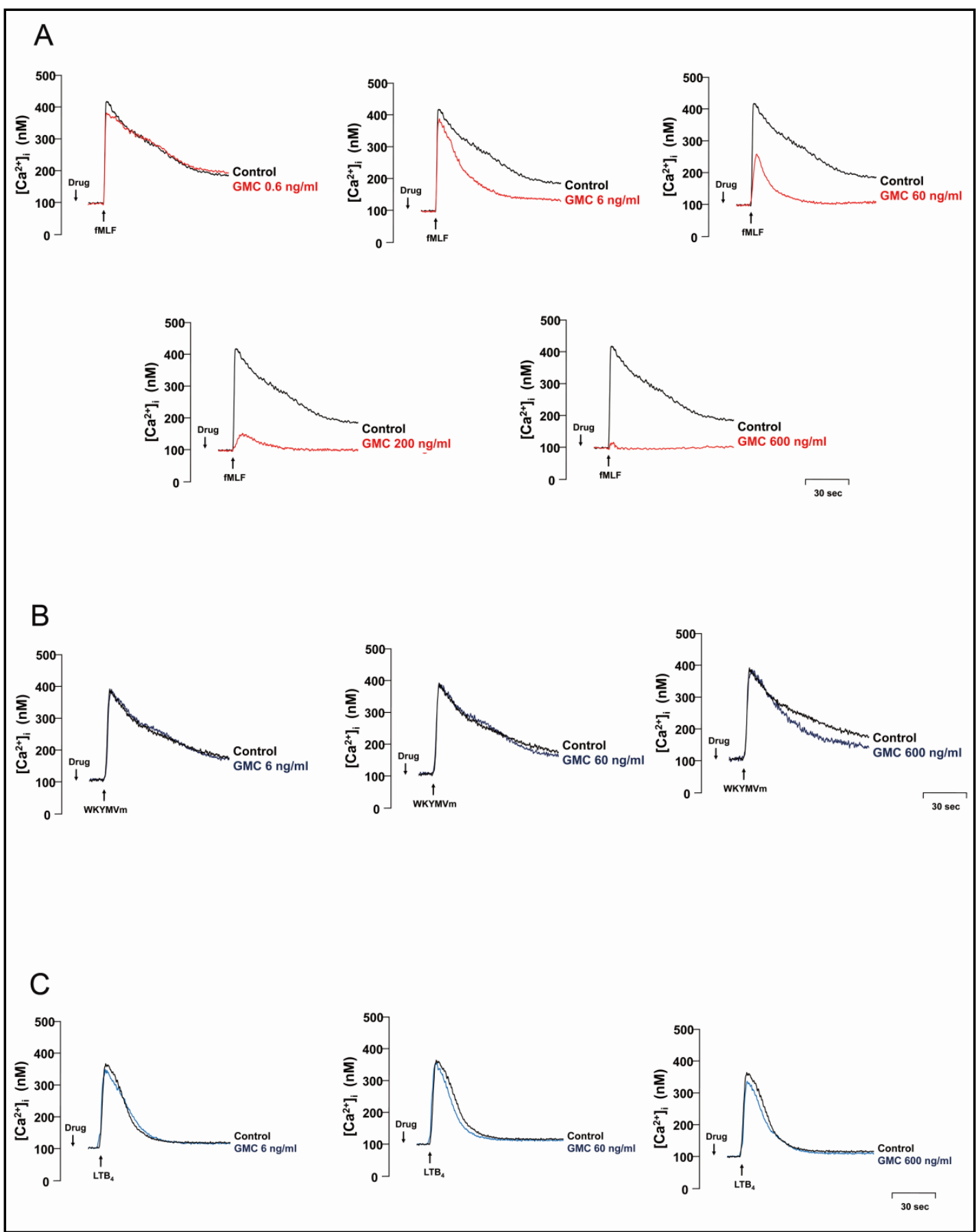

Fig. 7. GMC inhibits intracellular calcium mobilization specifically in fMLF-stimulated neutrophils. Neutrophils stained with fluo-3/AM $(2 \mu \mathrm{M})$ were treated with GMC and induced using (A) fMLF (100 nM), (B) WKYMVm (2 nM), or (C) LTB4 (100 nM). All experiments were conducted independently three to six times. 


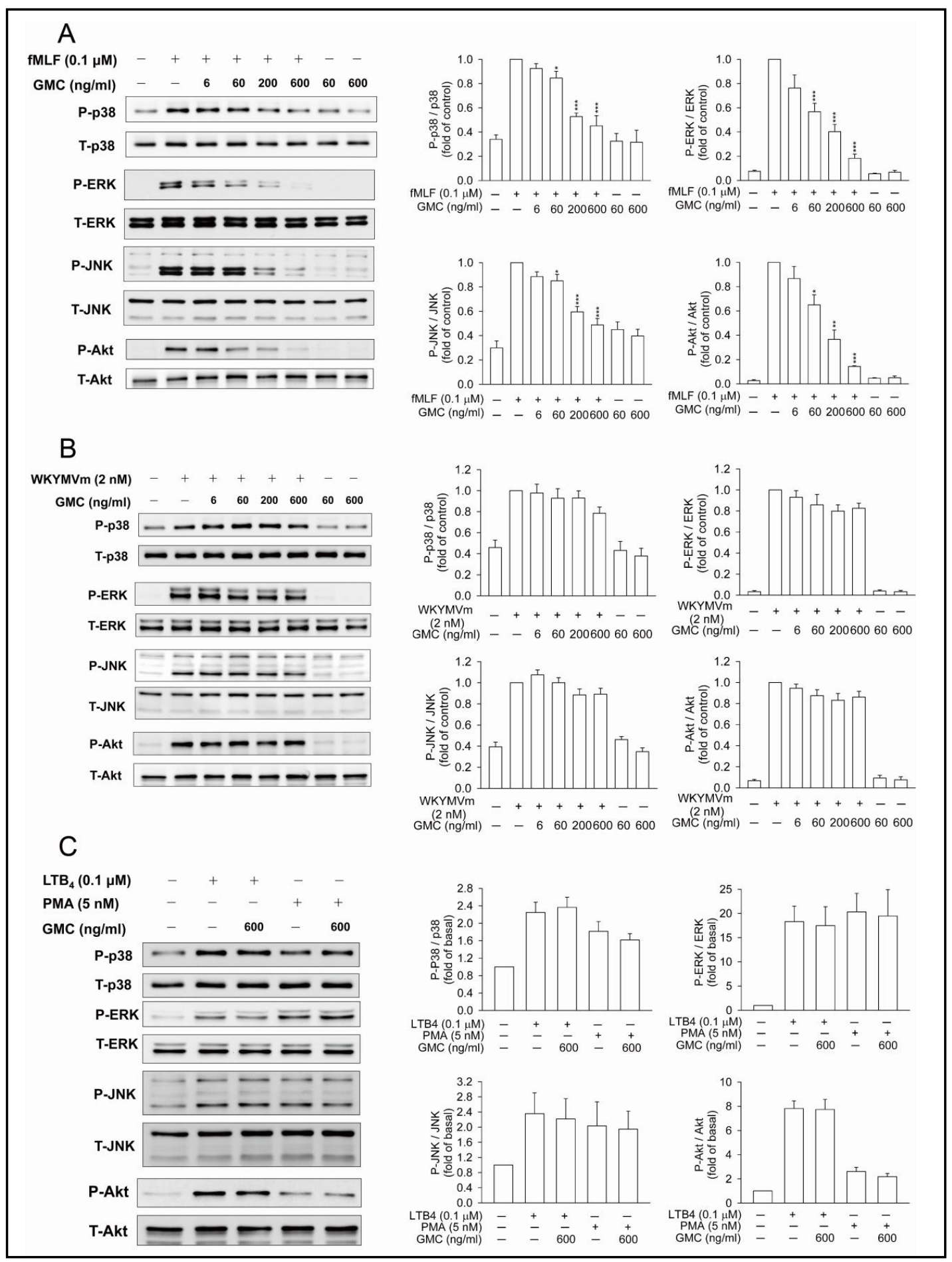

Fig. 8. GMC significantly suppresses the phosphorylation of MAPK and Akt protein in fMLF-stimulated neutrophils. Neutrophils were treated with GMC for $5 \mathrm{~min}$ and then stimulated for $1 \mathrm{~min}$ using (A) fMLF (100 nM), (B) WKYMVm (2 nM), (C) LTB4 (100 nM), or PMA (5 nM). Phosphorylation of p38, ERK, JNK, and Akt was assessed by immunoblotting using antibodies corresponding to the target proteins. The intensity of blotted proteins was determined using a densitometer and normalized to reference values obtained from the corresponding total protein values. All experiments were conducted independently four or five times. All data are summarized as mean \pm SEM compared with the control. ${ }^{*} \mathrm{p}<0.05,{ }^{* *} \mathrm{p}<0.01,{ }^{* * *} \mathrm{p}<0.001$ versus the corresponding control group. 
Fig. 9. GMC ameliorates lung inflammation in LPS-induced ALI mice. C57BL/6 male animals were intraperitoneally administered the vehicle or GMC (100 mg/kg) $1 \mathrm{~h}$ before LPS (160 ng/g) was sprayed into the trachea to induce ALI. All mice were divided into four groups: sham, GMC only, LPS only, and LPS+GMC. (A) Photomicrographic image showing hematoxylin \& eosinstained lung sections obtained using a light microscope with a 200x objective lens. Immunohistochemical staining of neutrophilic Ly-6G proteins indicated by arrows was also present in tissues. (B) Wetto-dry weight ratios of lung samples and (C) MPO activity.

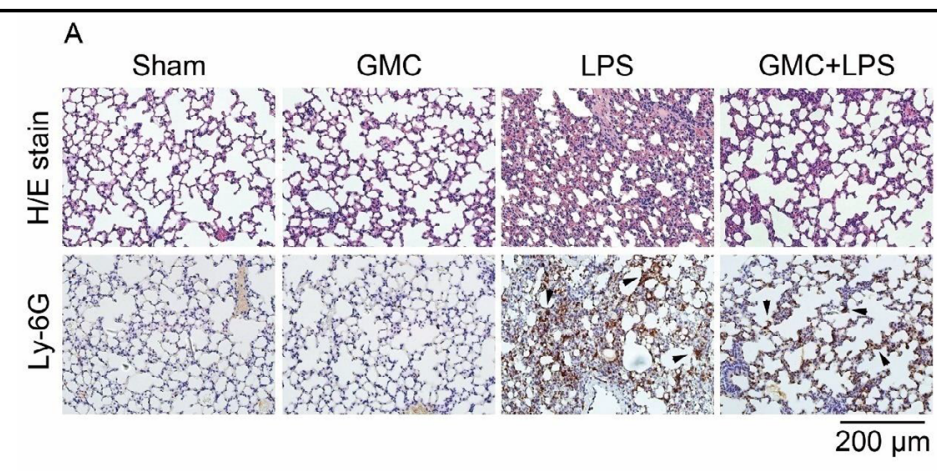

B

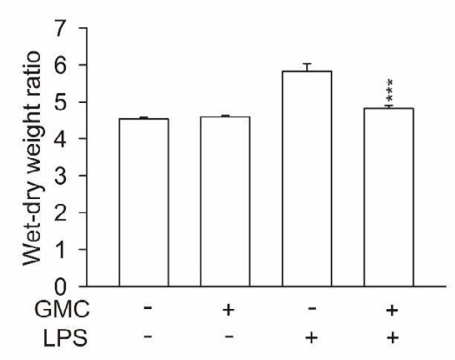

C

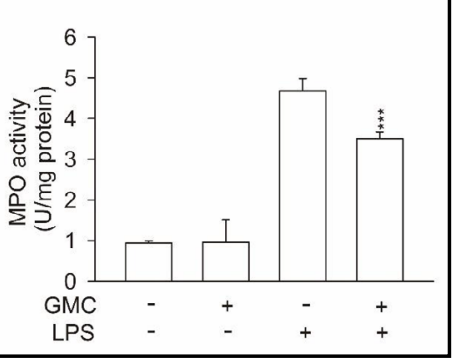

Values are expressed as mean \pm

SEM from six mice in each group. ${ }^{* * *} \mathrm{p}<0.001$ versus the LPS group.

\section{Discussion}

Exogenous pathogen infection or endogenous tissue damage induces neutrophil activation and the subsequent release of inflammatory mediators, thereby contributing to acute inflammatory responses $[25,26]$. Uncontrolled or poorly regulated acute inflammation in the lung can lead to lethal ALI and ARDS. Dysregulation of excess neutrophil activation and the resulting immune responses greatly impair pulmonary endothelial function and occupy airway space during inflammation [27]. FPRs, particularly FPR1, are responsible for recognizing different endogenous or exogenous molecular stimuli in neutrophils and play a critical role in mediating neutrophil activation. A growing body of evidence supports claims that FPR1 antagonists have promising anti-inflammatory effects $[28,29]$. In the present study, we demonstrate that a natural constituent extracted from G. multiflora Champ. strongly inhibits superoxide generation, elastase release, and ROS production by selectively and competitively blocking FPR1 in $N$-formyl peptide-stimulated cells. GMC also prevented LPS-induced ALI in our animal study. These findings suggest GMC as a novel FPR1 inhibitor that could help in the regulation of neutrophil-dominated inflammation.

GMC had concentration-dependent inhibitory effects on respiratory burst and elastase degranulation in fMLF-activated neutrophils. GMC decreased oxidative stress by limiting the extracellular release of superoxides and the intracellular generation of superoxides. In cellfree assays, we found that none of the aforementioned inhibitory effects were associated with free radical scavenging ability or drug cytotoxicity. The effects were clearly associated with FPR1-mediated downstream signaling pathways.

FPRs are G protein-coupled receptors that are expressed primarily on the cell membrane of phagocytes [8]. FPR1 and FPR2 are homologous receptors that are activated by binding to an $N$-formyl methionine motif, which is generated from bacterial membrane components or from endogenous mitochondria $[10,30]$. Infectious and sterile inflammation can both be initiated through FPR-mediated neutrophil activation. We used the well-known synthetic $N$-formyl peptide, fMLF, to study the involvement of FPR1 signaling transduction in neutrophil 


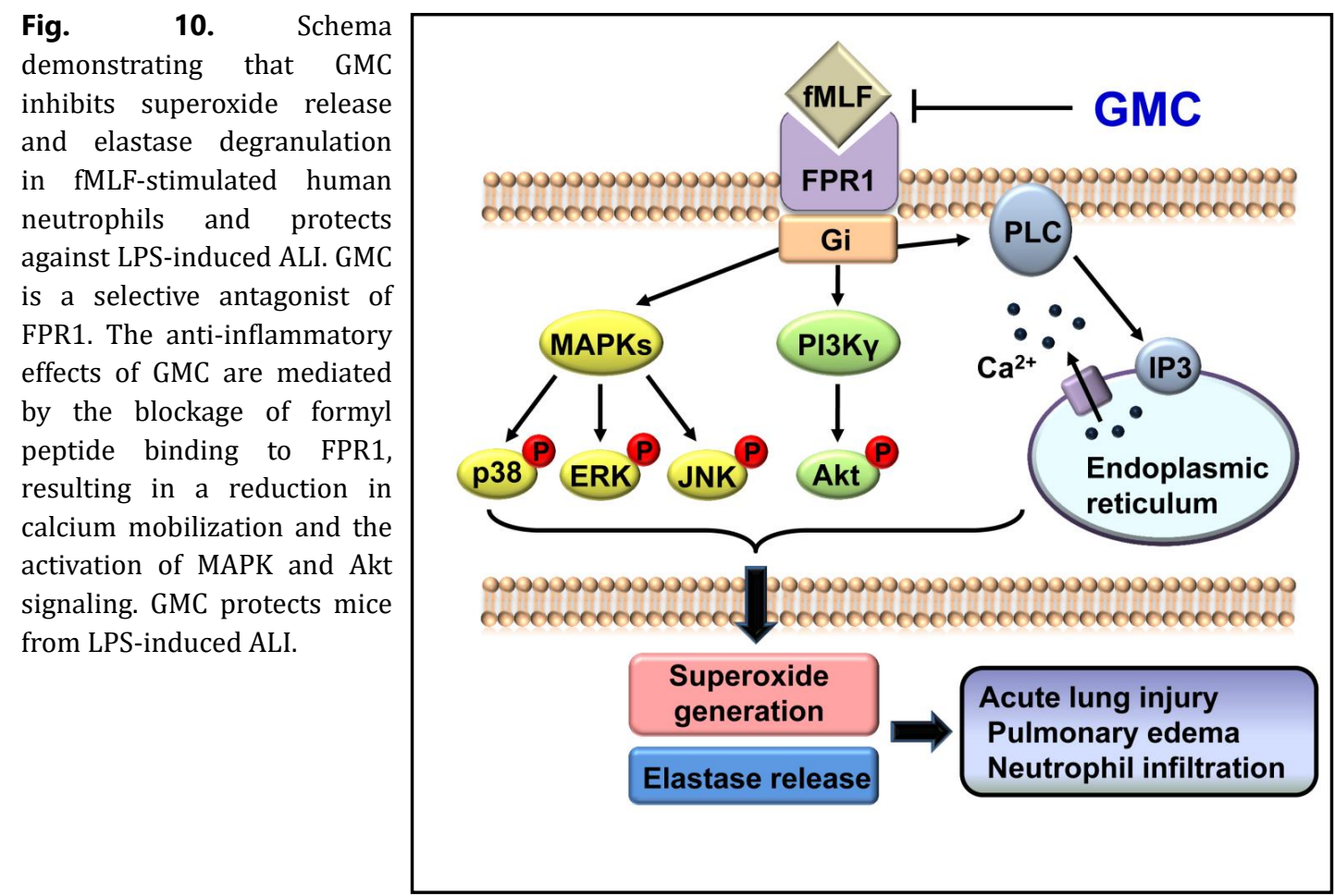

activation. Hexapeptide WKYMVm was used to assay FPR1- and FPR2-mediated neutrophil activation [31]. PMA, LTB4, and NaF were used as non-FPR agonists for neutrophils. Our results revealed that GMC exhibits inhibitory effects only in fMLF- or WKYMVm-activated neutrophils but not in other non-FPR agonist-activated neutrophils. Moreover, receptor binding assays revealed that GMC significantly inhibited the binding of fMLF to FPR1 in activated neutrophils. GMC also presented competitive binding to FPR1 with FNLFNYK in THP-1 and hFPR1-transfected HEK293 cells. These findings suggest that GMC is a potently competitive FPR1 antagonist.

Many downstream signaling pathways are transduced by FPR1, including cAMP/PKA, calcium mobilization, MAPK, and Akt signaling [11]. The PKA inhibitor H89 is unable to abolish the inhibitory effects of GMC on fMLF-induced superoxide anion production and elastase release. FPR1-mediated neutrophil activation increases intracellular cAMP concentrations, thereby reducing respiratory burst and elastase degranulation [20, 21]. Agents mediated by PKA signaling, such as PDE4 inhibitors, synergistically increase cAMP levels in fMLFstimulated neutrophils $[20,21]$. In our study, GMC showed inhibitory rather than synergistic effects in fMLF-induced increases in cAMP levels. Taken together, we can deduce that the cAMP/PKA signaling pathway is not involved in these inhibitory effects of GMC in neutrophils. We subsequently assessed the effects of the FPR1-mediated downstream signaling pathway on neutrophil activation to identify the mechanisms underlying the protective effects of GMC, including intracellular calcium mobilization, MAPK, and PI3K/Akt pathways [32]. All of these signaling pathways mediate diverse immune responses in FPR1-stimulated neutrophils $[23,32,33]$. GMC dose-dependently decreased the concentration of the peak calcium influx in fMLF-stimulated neutrophils but not in non-FPR1 agonist-stimulated neutrophils. In western blot assays, GMC had concentration-dependent inhibitory effects on MAPK and Akt phosphorylation in fMLF-stimulated neutrophils but not in WKYMVm- or LTB4-activated cells. Our results support our hypothesis that GMC inhibits fMLF-induced superoxide anion release, elastase degranulation, and ROS production in human neutrophils. The mediation of these inhibitory effects is enabled by blockade of the downstream pathways of FPR1.

$\mathrm{N}$-formyl peptides may facilitate neutrophil mobilization and recruitment to sites of inflammation, resulting in lung damage $[34,35]$. Chemotaxis and the migration of fMLF- 


\section{Cellular Physiology Cell Physiol Biochem 2018;51:2776-2793 \begin{tabular}{ll|l} 
and Biochemistry & $\begin{array}{l}\text { DOl: 10.1159/000495970 } \\
\text { Publisned onlne: IL December } 2018\end{array}$ & $\begin{array}{l}\text { O 2018 The Author(s). Published by S. Karger AG, Basel } \\
\text { www.karger.com/cpb }\end{array}$ \\
\cline { 2 - 3 }
\end{tabular} \\ Tsai et al.: A Novel FPR1 Antagonist GMC Inhibits Neutrophilic Inflammation}

stimulated neutrophils are both absent in FPR knockout mice [36]. FPR1 signaling facilitates neutrophil activation and infiltration in endotoxin-induced ALI, and FPR1 antagonists alleviate pulmonary damage and edema $[13,16]$. In the present study, we evaluated the antiinflammatory effects and therapeutic value of GMC in a mouse model of LPS-induced ALI. LPS and AMLF are components of bacterial membranes that chemotactically attract neutrophils into inflamed lung tissue during the progression of pathogenesis. LPS triggers marked immune reactions, leading to ALI or septic shock, which have high mortality rates [37]. The severity of LPS-induced ALI is closely related to neutrophil activation and infiltration in the lung [38]. Our findings suggest that GMC decreases alveolar wall disruption, pulmonary hemorrhage and edema, and neutrophil infiltration among mice with ALI-induced LPS. Our results indicate GMC as a novel FPR1 inhibitor, with the potential to cure neutrophil-related inflammation.

\section{Conclusion}

The results obtained in this study demonstrate that GMC acts as a natural selective FPR1 inhibitor. GMC markedly suppresses the expressions of superoxide anion, reactive oxidants derived therefrom, and elastase in fMLF-stimulated human neutrophils. All inhibitory effects are mediated by blockade of FPR1 binding, which also reduces calcium mobilization and MAPK and Akt activation (Fig. 10). Our results suggest the potential development of GMC as a therapeutic treatment for critically lethal ALI.

\section{Abbreviations}

ALI (acute lung injury); Akt (protein kinase B); ARDS (acute respiratory distress syndrome); cAMP (cyclic adenosine monophosphate); CB (cytochalasin B); DMSO (dimethyl sulfoxide); FBS (fetal bovine serum); DPPH (dipenyl picrylhydrazyl); FACS (fluorescenceactivated cell sorting); fMLF ( $N$-formyl-L-methionyl-L-leucyl-L-phenylalanine); FNLFNYK ( $N$-formyl-Nle-Leu-Phe-Nle-Tyr-Lys-fluorescein); FPR (formyl peptide receptor); GMC (fruit extraction from Garcinia multiflora Champ); H89 (N-[2-(p-Bromocinnamylamino) ethyl]-5-isoquinolinesulfonamide); HBSS (Hank's balanced salts solution); HPLC (high performance liquid chromatography); IC50 (half maximal inhibitory concentration); LDH (lactate dehydrogenase); LPS (lipopolysaccharide); LTB4 (leukotriene B4); MAPK (mitogenactivated protein kinase); MFI (mean fluorescence intensity); MPO (myeloperoxidase); NAF (sodium fluoride); PAF (platelet-activating factor); PKA; protein (kinase A); PMA (phorbol myristate acetate); RPMI (Roswell Park Memorial Institute); ROS (reactive oxygen species); SEM (standard error of the mean); SOD (superoxide dismutase); WKYMVm (Trp-Lys-TyrMet-Val-D-Met); WST-1 (water soluble tetrazolium-1.).

\section{Acknowledgements}

This study was supported by the grants from the Ministry of Science Technology (MOST 106-2320-B-255-003-MY3, MOST 104-2320-B-255-004-MY3, and MOST 106-2320-B-182A002-MY2), Ministry of Education (EMRPD1G0231), and Chang Gung Memorial Hospital (CMRPF1F0011 3, CMRPF1F0061 3, CMRPG3G1201, and BMRP450), Taiwan.

\section{Disclosure Statement}

The authors declare that no conflicts of interest exist. 


\section{Cellular Physiology Cell Physiol Biochem 2018;51:2776-2793 \begin{tabular}{ll|l} 
and Biochemistry Published onlIne: I2 December 2018 & $\begin{array}{l}\text { @ 2018 The Author(s). Published by S. Karger AG, Basel } \\
\text { www.karger.com/cpb }\end{array}$ \\
\hline
\end{tabular}}

\section{References}

1 von Andrian UH, Berger EM, Ramezani L, Chambers JD, Ochs HD, Harlan JM, Paulson JC, Etzioni A, Arfors KE: In vivo behavior of neutrophils from two patients with distinct inherited leukocyte adhesion deficiency syndromes. J Clin Invest 1993;91:2893-2897.

2 Bai J, Tang L, Lomas-Neira J, Chen Y, McLeish KR, Uriarte SM, Chung CS, Ayala A: TAT-SNAP-23 treatment inhibits the priming of neutrophil functions contributing to shock and/or sepsis-induced extra-pulmonary acute lung injury. Innate Immun 2015;21:42-54.

-3 Tsai YF, Hwang TL: Neutrophil elastase inhibitors: a patent review and potential applications for inflammatory lung diseases (2010 - 2014). Expert Opin Ther Pat 2015;25:1145-1158.

-4 Wang Y, Xiao Y, Zhong L, Ye D, Zhang J, Tu Y, Bornstein SR, Zhou Z, Lam KS, Xu A: Increased neutrophil elastase and proteinase 3 and augmented NETosis are closely associated with beta-cell autoimmunity in patients with type 1 diabetes. Diabetes 2014;63:4239-4248.

5 Wiener-Kronish JP, Gropper MA, Matthay MA: The adult respiratory distress syndrome: definition and prognosis, pathogenesis and treatment. Br J Anaesth 1990;65:107-129.

6 Davey A, McAuley DF, O’Kane CM: Matrix metalloproteinases in acute lung injury: mediators of injury and drivers of repair. Eur Respir J 2011;38:959-970.

7 Tiruvoipati R, Botha J, Peek G: Effectiveness of extracorporeal membrane oxygenation when conventional ventilation fails: valuable option or vague remedy? J Crit Care 2012;27:192-198. Le Y, Murphy PM, Wang JM: Formyl-peptide receptors revisited. Trends Immunol 2002;23:541-548.

-9 Migeotte I, Communi D, Parmentier M: Formyl peptide receptors: a promiscuous subfamily of G proteincoupled receptors controlling immune responses. Cytokine Growth Factor Rev 2006;17:501-519.

10 Carp H: Mitochondrial N-formylmethionyl proteins as chemoattractants for neutrophils. J Exp Med 1982;155:264-275.

11 Dorward DA, Lucas CD, Chapman GB, Haslett C, Dhaliwal K, Rossi AG: The role of formylated peptides and formyl peptide receptor 1 in governing neutrophil function during acute inflammation. Am J Pathol 2015;185:1172-1184.

12 Tsai YF, Yang SC, Hwang TL: Formyl peptide receptor modulators: a patent review and potential applications for inflammatory diseases (2012-2015). Expert Opin Ther Pat 2016;10.1080/13543776.2016.12165461-18.

13 Yang SC, Chang SH, Hsieh PW, Huang YT, Ho CM, Tsai YF, Hwang TL: Dipeptide HCH6-1 inhibits neutrophil activation and protects against acute lung injury by blocking FPR1. Free Radic Biol Med 2017;106:254-269.

14 Selvatici R, Falzarano S, Mollica A, Spisani S: Signal transduction pathways triggered by selective formylpeptide analogues in human neutrophils. Eur J Pharmacol 2006;534:1-11.

15 Wenceslau CF, McCarthy CG, Szasz T, Goulopoulou S, Webb RC: Mitochondrial N-formyl peptides induce cardiovascular collapse and sepsis-like syndrome. Am J Physiol Heart Circ Physiol 2015;308:H768-777.

16 Grommes J, Drechsler M, Soehnlein 0: CCR5 and FPR1 mediate neutrophil recruitment in endotoxininduced lung injury. J Innate Immun 2014;6:111-116.

>17 Ting CW, Hwang TL, Chen IS, Cheng MJ, Sung PJ, Yen MH, Chen JJ: Garcimultiflorone G, a novel benzoylphloroglucinol derivative from Garcinia multiflora with inhibitory activity on neutrophil proinflammatory responses. Chem Biodivers 2014;11:819-824.

-18 Lin YM, Anderson H, Flavin MT, Pai YH, Mata-Greenwood E, Pengsuparp T, Pezzuto JM, Schinazi RF, Hughes SH, Chen FC: In vitro anti-HIV activity of biflavonoids isolated from Rhus succedanea and Garcinia multiflora. J Nat Prod 1997;60:884-888.

19 Ting CW, Hwang TL, Chen IS, Yen MH, Chen JJ: A new benzoylphloroglucinol derivative with an adamantyl skeleton and other constituents from Garcinia multiflora: effects on neutrophil pro-inflammatory responses. Chem Biodivers 2012;9:99-105.

20 Tsai YF, Chu TC, Chang WY, Wu YC, Chang FR, Yang SC, Wu TY, Hsu YM, Chen CY, Chang SH, Hwang TL: 6-Hydroxy-5, 7-dimethoxy-flavone suppresses the neutrophil respiratory burst via selective PDE4 inhibition to ameliorate acute lung injury. Free Radic Biol Med 2017;106:379-392.

21 Tsai YF, Yu HP, Chung PJ, Leu YL, Kuo LM, Chen CY, Hwang TL: Osthol attenuates neutrophilic oxidative stress and hemorrhagic shock-induced lung injury via inhibition of phosphodiesterase 4. Free Radic Biol Med 2015;89:387-400. 


\section{Cellular Physiology Cell Physiol Biochem 2018;51:2776-2793

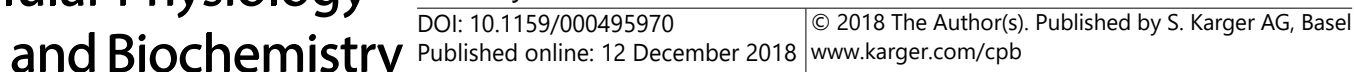

-22 Gupta AK, Giaglis S, Hasler P, Hahn S: Efficient neutrophil extracellular trap induction requires mobilization of both intracellular and extracellular calcium pools and is modulated by cyclosporine A. PLoS One 2014;9:e97088.

23 Tintinger G, Steel HC, Anderson R: Taming the neutrophil: calcium clearance and influx mechanisms as novel targets for pharmacological control. Clin Exp Immunol 2005;141:191-200.

24 Arnhold J: Properties, functions, and secretion of human myeloperoxidase. Biochemistry (Mosc) 2004;69:4-9.

-25 Boulay F, Tardif M, Brouchon L, Vignais P: Synthesis and use of a novel N-formyl peptide derivative to isolate a human N-formyl peptide receptor cDNA. Biochem Biophys Res Commun 1990;168:1103-1109. Hazeldine J, Hampson P, Lord JM: The impact of trauma on neutrophil function. Injury 2014;45:1824-1833. Tate MD, Deng YM, Jones JE, Anderson GP, Brooks AG, Reading PC: Neutrophils ameliorate lung injury and the development of severe disease during influenza infection. J Immunol 2009;183:7441-7450.

28 Kao W, Gu R, Jia Y, Wei X, Fan H, Harris J, Zhang Z, Quinn J, Morand EF, Yang YH: A formyl peptide receptor agonist suppresses inflammation and bone damage in arthritis. Br J Pharmacol 2014;171:4087-4096.

29 Schepetkin IA, Kirpotina LN, Khlebnikov AI, Cheng N, Ye RD, Quinn MT: Antagonism of human formyl peptide receptor 1 (FPR1) by chromones and related isoflavones. Biochem Pharmacol 2014;92:627-641.

-30 Marasco WA, Phan SH, Krutzsch H, Showell HJ, Feltner DE, Nairn R, Becker EL, Ward PA: Purification and identification of formyl-methionyl-leucyl-phenylalanine as the major peptide neutrophil chemotactic factor produced by Escherichia coli. J Biol Chem 1984;259:5430-5439.

31 Christophe T, Karlsson A, Dugave C, Rabiet MJ, Boulay F, Dahlgren C: The synthetic peptide Trp-Lys-TyrMet-Val-Met-NH2 specifically activates neutrophils through FPRL1/lipoxin A4 receptors and is an agonist for the orphan monocyte-expressed chemoattractant receptor FPRL2. J Biol Chem 2001;276:21585-21593.

-32 Korkmaz S, Erturan I, Naziroglu M, Uguz AC, Cig B, Ovey IS: Colchicine modulates oxidative stress in serum and neutrophil of patients with Behcet disease through regulation of $\mathrm{Ca}(2)(+)$ release and antioxidant system. J Membr Biol 2011;244:113-120.

-33 Chen LW, Lin MW, Hsu CM: Different pathways leading to activation of extracellular signal-regulated kinase and p38 MAP kinase by formyl-methionyl-leucyl-phenylalanine or platelet activating factor in human neutrophils. J Biomed Sci 2005;12:311-319.

-34 Bleyl JU, Heller AR, Fehrenbach A, Heintz M, Fehrenbach H, Klenz G, Gama de Abreu M, Hubler M, Spieth PM, Koch T: Pretreatment with perfluorohexane vapor attenuates fMLP-induced lung injury in isolated perfused rabbit lungs. Exp Lung Res 2010;36:342-351.

-35 Schiffmann E, Showell HV, Corcoran BA, Ward PA, Smith E, Becker EL: The isolation and partial characterization of neutrophil chemotactic factors from Escherichia coli. J Immunol 1975;114:1831-1837.

-36 Gao JL, Lee EJ, Murphy PM: Impaired antibacterial host defense in mice lacking the N-formylpeptide receptor. J Exp Med 1999;189:657-662.

-37 Michie HR, Manogue KR, Spriggs DR, Revhaug A, O'Dwyer S, Dinarello CA, Cerami A, Wolff SM, Wilmore DW: Detection of circulating tumor necrosis factor after endotoxin administration. N Engl J Med 1988;318:1481-1486.

-38 Yoshikawa T, Takano H, Takahashi S, Ichikawa H, Kondo M: Changes in tissue antioxidant enzyme activities and lipid peroxides in endotoxin-induced multiple organ failure. Circ Shock 1994;42:53-58. 